\title{
OS DIREITOS AUTORAIS EM DISCUSSÃO NO BRASIL DURANTE O SÉCULO XIX
}

Jean Bastardis ${ }^{1}$

Os leitores brasileiros do século XIX não possuíam informações inteiramente claras quanto ao papel desempenhado pelo tradutor e à sua interferência nos textos finais. Os autores dos textos, muitas vezes, não eram claramente explicitados, nem os créditos de tradução eram precisos. Disto decorria uma série de dúvidas relacionadas à autoria, bem como à fidelidade das traduções que chegavam ao Brasil.

A indefinição a respeito das ações de tradução, adaptação e autoria era grande e motivava raciocínios que confundiam e relativizavam estas práticas a respeito dos textos literários. Por essa razão, Francisco de Paula Brito podia afirmar, na abertura de um dos folhetins publicados pelo Jornal do Commercio, em 1839, "não compusemos, não traduzimos, nem abreviamos um romance. E todavia compusemos, traduzimos e abreviamos um romance" ${ }^{2}$. Isto queria dizer que muito do que seria publicado a seguir, no folhetim $O$ pontífice e os carbonários ${ }^{3}$ resultava de uma adaptação pouco ortodoxa, tendo em vista que Paula Brito afirmava: "o fundo da presente composição não é nosso, e muitas de suas páginas são literalmente traduzidas, porém algumas ideias são nossas". ${ }^{4}$ Certamente, definir em relação ao trabalho publicado o que resultava da autoria de Paula Brito ou de Alexandre Dumas não era uma questão de fácil solução. Tal problema permite-nos compreender porque tais adaptações também eram perigosas para o estabelecimento da literatura nacional, uma vez que era nessas ações, de troca pouco definidas com a produção estrangeira, que se buscava dar os primeiros passos numa atividade literária propriamente brasileira.

Com vistas a ultrapassar esse tipo de problema e com interesse de afirmar a importância da figura autoral, foi que se promoveram discussóes acerca da vantagem de se desenvolver, no Brasil, a doutrina dos direitos autorais. Sua definição como norma procurava controlar a escrita literária por meio da identificação de responsabilidades $e$, por outro lado, prover garantias à propriedade do texto publicado, além de elevar a consideração sobre o trabalho letrado. No processo de estabelecimento do mercado literário brasileiro no século XIX, foi se construindo entre literatos, leitores e editores a compreensão da propriedade literária e, posteriormente, dos chamados direitos autorais.

Como questão legal, o acompanhamento da legislação sobre a proteção da propriedade intelectual apresenta-se como caminho mais evidente e eficaz. No entanto, acompanhar ambientes de discussão variados, tais como as discussões legislativas e a publicação jornalística sobre a questão, ainda que não resultassem na efetivação de leis que protegessem os autores, permite vislumbrar negociações que

\footnotetext{
${ }^{1}$ Doutor em História Social pelo PPGHIS-UFRJ. E-mail: <jeanbastardis@gmail.com>.

2 PAULA BRITO, Francisco de. Folhetim. Jornal do Commercio, 31/07/1839. O Pontífice e os carbonários foi veiculado no Jornal do Commercio, de 31/07/1839 a 13/08/1839.

${ }^{3}$ O Pontífice e os carbonários foi veiculado no Jornal do Commercio, de 31/07/1839 a 13/08/1839.

${ }^{4}$ PAULA BRITO, Folhetim...
} 
evidenciam a construção da abordagem brasileira do problema dos direitos dos autores sobre suas obras. Na perspectiva das disputas sobre o direito autoral, cabe analisar os principais passos para a definição legal das atribuições dos autores frente à legislação constituída ao longo do século XIX no Brasil.

Desde a Constituição de 1824 a proteção aos inventores era garantida e sua desobediência resultava em punição. Sem, contudo, referir-se explicitamente à propriedade intelectual, na prática o problema persistia, deixando autores e editores sem ação efetiva diante de desrespeitos a esse direito. Como resposta não só às ocorrências danosas ao estabelecimento do negócio do livro no Brasil, foram desenvolvidas limitações à impressão, à circulação e à negociação de obras literárias.

Frequentemente os estudos sobre o tema ${ }^{5}$ localizam o primeiro tratamento da questão como sendo a Lei de 11 de agosto de 1827, que criou cursos de direito em São Paulo e em Olinda. Em seu artigo $7^{\circ}$, a lei tratava dos compêndios que poderiam ser produzidos pelos lentes dos cursos, assegurando o privilégio exclusivo de suas obras pelo prazo de dez anos. Que o artigo tinha relação com os direitos de autores, não há dúvida, mas considerá-lo como primeiro ato em defesa de direitos autorais no país seria ir longe demais. Como a própria formulação da lei adiantava, tratava-se mais da aplicação do antigo privilégio e não de uma formulação legal que garantisse direitos de autores sobre seus textos impressos.

Efetivamente, a matéria foi abordada legalmente apenas em 1830, quando o Código Criminal do Império criminalizou impressões realizadas sem autorização de seus autores. No título III de sua terceira parte, que tratava dos crimes contra a propriedade, proibia-se a reprodução de escritos ou de estampas feitos, compostos ou traduzidos por cidadãos brasileiros. Ignorando produções de autores estrangeiros, a proteção durava enquanto vivesse o autor $e$, a seguir, por um período de dez anos após sua morte, caso existissem herdeiros.

A concretização de tais direitos, no entanto, foi limitada na maioria das vezes aos interesses de editores, tendo em vista que as condições de publicação experimentadas no Brasil foram historicamente desfavoráveis aos autores. Resignados, os escritores tinham poucas opções para a exposição de seus trabalhos e entregavam seus manuscritos aos editores por intermédio de contratos pouco vantajosos. Como resultado, foram transferidos a eles quaisquer direitos sobre seus escritos em troca de quantias diminutas. Quem se envolvia na defesa de direitos relacionados à propriedade dos textos eram, na maioria das vezes, os editores, reforçando a dimensão econômica sobre qualquer outra, tal como estava expresso na legislação relacionada.

A debilidade do tratamento dispensado aos direitos autorais continuou até a década de 1850, quando foram propostas duas leis que visavam garantir a propriedade literária aos autores brasileiros. Em 1856, Aprígio Guimarães apresentou uma proposta de lei. Seguindo parte do tratamento internacional sobre a matéria, que evoca inclusive quando apresenta seu projeto, ${ }^{6}$ defendia o gozo vitalício da

\footnotetext{
${ }^{5}$ STAUT JÚNIOR, Sérgio Said. Direitos autorais: entre as relações sociais e jurídicas. Curitiba: Moinho de Verbo, 2006.

${ }^{6}$ ANNAES DO PARLAMENTO BRASILEIRO. Câmara dos Srs. Deputados. Quarto ano da nona legislatura. Sessão de 1856. Tomo IV. Rio de Janeiro. Typographia de Hyppolito José Pinto \& C.
} 
propriedade literária e estendia para trinta anos o prazo de gozo pelos herdeiros ou pelos editores representantes dos autores mortos. O projeto defendia direitos iguais para estrangeiros que publicassem em português no Brasil, além de recomendar um acordo literário entre Brasil e Portugal para combater contrafações existentes no mercado. Estas transgressões afrontavam principalmente os interesses de autores portugueses, uma vez que o mercado brasileiro era bastante visado por negociantes. $\mathrm{Na}$ Revista Lisbonense, em 1847, comentava-se a questão, ressaltando que as afrontas contra os direitos de autores e editores portugueses avançavam sobre coleções inteiras $^{7}$. No entanto, se as contrafações brasileiras eram prejudiciais aos portugueses, o deputado argumentava que a prática seria perniciosa também para o desenvolvimento das Letras no Brasil, uma vez que o acesso facilitado às obras estrangeiras resultava num tropeço à publicação de autores nacionais.

O projeto de Guimarães tratava também das condições para que herdeiros e editores pudessem gozar dos direitos após a morte do autor e procurava definir as formas de registro que garantissem aqueles direitos. Outra contribuição importante no domínio da discussão sobre os direitos de autores foi a indicação de práticas que deveriam ser consideradas como contrafação no âmbito das produções intelectuais no Brasil. No artigo $3^{\circ}$ do projeto, Guimarães incluiu as ações comerciais que faziam circular no mercado brasileiro os livros contrafeitos em outros países e a impressão $e$ divulgação de cartas particulares sobre assuntos literários ou científicos, resultantes de invenção, como ações de contrafação.

A designação era também estendida à reimpressão não autorizada de obras alheias, bem como à divulgação impressa de sermões, discursos, aulas e outros tipos de comunicações sem anuência do autor. Usos não autorizados de trechos de obras alheias ou de extratos sem autorização em jornais, revistas e qualquer publicação periódica também eram qualificados como contrafação.

Apesar de não ter resultado numa efetiva regulação das práticas literárias, o projeto de Aprígio Guimarães colocou em cena a discussão do problema de forma sistematizada e alimentou o debate sobre os direitos autorais. Posteriormente, muito dos que voltaram ao tema na esfera legislativa fizeram referência a seu projeto e sua justificação. Na opinião de colegas deputados e da imprensa, seu projeto foi utilizado como base no ano seguinte por outro deputado, Bernardo Avelino Gavião Peixoto, deputado por São Paulo.

Peixoto discutiu, em 1857, o projeto de uma lei que buscava garantir o gozo dos direitos autorais aos escritores brasileiros. O deputado argumentava que, até aquele momento, houvera tônica na defesa apenas do retorno econômico aos empreendimentos literários, como qualifica, por exemplo, as companhias teatrais ${ }^{8}$.

Considerando o teatro como um importante lugar de consumo literário, defendia uma nova interpretação do fazer literário, por exemplo, propondo a necessidade de registro comercial das companhias teatrais como forma de garantia de sua

1875. Disponível em http://imagem.camara.gov.br/dc_20b.asp?selCodColecaoCsv=A\&Datain= 1/8/1856\#. Acesso em 08/06/2016, p. 170.

${ }^{7}$ HALLEWELL, Lawrence. O livro no Brasil: sua história. 3 ed. São Paulo: EDUSP, 2012, p. 270.

8 PEIXOTO, Bernardo Avelino Gavião. Apresentação de projetos. Annaes do Parlamento Brazileiro, Câmara dos Srs. deputados. t. 5, 1857. Rio de Janeiro: Typ. Do Imparcial e Constitucional de J. Villeneuve e Comp., 1857, p. 45-50. 
estabilidade econômica, além de mudanças na forma de pagamento de direitos aos autores de peças teatrais. Em seu discurso, o deputado apresenta razões que o levavam a compreender o costume vigente, de destinar a renda de apresentaçóes pontuais como pagamento aos autores, como prejudicial ao teatro brasileiro, aos agentes envolvidos e, mais ainda, aos escritores. O deputado argumentava que

[...] sendo o teatro [...] geralmente compreendido como a fórmula literária mais ao gosto do público, mais consentânea com a natureza dos povos, e por isso mesmo a mais influente em seu espírito [...]; sendo igualmente verdade que os costumes de um povo modelam-se e formam-se segundo suas instituições; parece-me evidente que empregar todos os meios possíveis para a boa organização dos teatros, é menos uma superabundância de cuidado que um rigoroso dever. Por isso no projeto que apresento sobre esta matéria obrigo as empresas e direções teatrais a ter uma escrituração mercantil registrada no tribunal do comércio e a outras obrigações mais, em benefício dos escritores dramáticos, $e$ animar as produções brasileiras. ${ }^{9}$

Expondo uma compreensão do teatro que poderíamos qualificar de "civilizacional", Gavião Peixoto defendeu que a maneira de conduzir os negócios teatrais deveria ser mais bem cuidada, uma vez que cumpririam uma função formativa. A atenção dispensada ao assunto tinha o objetivo de organizar uma atividade intelectual. Estabelecendo regras para o pagamento daqueles que criavam, pretendia Gavião Peixoto que novos costumes fossem produzidos entre empresários e autores, resultando na geração de peças de melhor qualidade. O deputado aplicava certa lógica de mercado à produção teatral, uma vez que entendia que a melhor remuneração dos autores geraria melhores obras. Os empresários não empregariam seus recursos em peças arriscadas, com qualidade questionável, $e$ isso favoreceria o financiamento mais cauteloso que buscaria textos de melhor categoria.

A questão da subsistência dos escritores também estava presente em sua fala. $\mathrm{O}$ deputado consternava-se com o fato de que os autores ficassem impedidos de decidir sobre as obras que escreviam, em troca de minguados pagamentos. Era comum que transmitissem toda a propriedade sobre seus textos aos empresários, que ficavam livres para explorar a representação dos textos teatrais como bem entendessem. A questão se impunha com maior força no caso de dramas de qualidade questionável, pois segundo defendeu o deputado,

[...] uma peça para ser bem montada demanda despesas, $e$ às vezes grandes despesas. [...] $\mathrm{O}$ empresário, iludido ou traído por sua ignorância ou boa fé aceita um drama desse gosto. Monta-o; desagrada a concorrência das duas primeiras noites [...], salvará possivelmente os gastos que tenha feito,

\footnotetext{
${ }^{9}$ PEIXOTO, Apresentação de projetos..., p. 48.
} 
mas nada lucrará, nem moralmente, porque seu teatro se desacredita, nem pecuniariamente, porque seu trabalho não foi recompensado. Aí resta a terceira noite do autor; aí tirará ele o que tirar, pouco importa; aí se abre o caminho à mediocridade, à ignorância, à especulação literária, ao passo que as inteligências serviçais ficarão silenciosas, ou banidas. ${ }^{10}$

Textos ruins resultariam na desqualificação dos escritores bem como das companhias. Por isso, considerava necessário garantir condições para a realização de bons investimentos literários; permitir que os autores pudessem criar sem que lhes fosse necessário envolver-se em trabalhos menores para garantir sua subsistência. No fundo, seu discurso carregava a mesma atenção essencialmente econômica normalmente dispensada à questão dos direitos autorais. Quanto aos escritores, assumia a preocupação por sua situação econômica e social, visto que considerava que sua única riqueza seria o talento, meio pelo qual poderiam prover sua subsistência. A retribuição econômica a esse trabalho, portanto, constituiria não mais do que uma compensação. Gavião Peixoto propunha uma nova forma de compensação aos autores, baseada na retribuição percentual do lucro obtido com seus textos, fixada em dez por cento da renda total. No entanto, a paga pelo trabalho intelectual implicado na criação dos textos literários constituía apenas um dos problemas relacionados à propriedade dos autores sobre sua obra.

Outro direito era também ignorado. Gavião Peixoto referia-se à possibilidade de legar em herança os direitos sobre os textos. Segundo o deputado, o empresário que morresse poderia estar despreocupado quanto à continuidade do gozo de sua propriedade, mas o mesmo não acontecia com os escritores. Tal situação impedia que os familiares de autores se vissem amparados diante do desaparecimento desses homens, e sobre isso indaga o deputado:

Os que em sua vida apenas tiveram sua inteligência $e$ sua pena para com elas e com seu suor quotidiano ganharem o pão de seu presente: o que deixarão a seus filhos como herança? Só a lembrança gloriosa de seu nome com a miséria por sócia? Só a admiração de sua glória acompanhada para sua descendência com o legado das privações e da desonra? ${ }^{11}$

Era incluído, portanto, outro direito que dizia respeito ao gozo da propriedade de forma mais completa. Ao estendê-la também aos herdeiros, buscava-se fortalecer o legado deixado por esses homens. Apenas dessa maneira os autores se veriam livres para estabelecer uma família e desenvolver suas atividades sem a preocupação de deixar-lhes um futuro incerto. À honra da glória literária alcançada pelo autor como resultado da qualidade de seus escritos aliava-se, por sua proposta, a possibilidade da honra econômica. Sem resultado prático, a apresentação do projeto de lei de Gavião

${ }^{10}$ PEIXOTO, Apresentação de projetos..., p. 48.
${ }^{11}$ PEIXOTO, Apresentação de projetos..., p. 48. 
Peixoto não surtiu efeito sobre a situação dos direitos autorais. $\mathrm{O}$ insucesso demonstrou a dificuldade da abordagem desse tema no meio intelectual brasileiro, mas não definiu o tratamento da questão.

José de Alencar apresentou, em 1875, uma nova proposta de lei relativa à propriedade literária ${ }^{12}$. Diferentemente de iniciativas anteriores, o projeto trazia como anexo uma fundamentação bastante longa em que discutia aspectos atinentes à lei proposta. Alencar propôs, já no primeiro artigo, as determinações mais urgentes $e$ polêmicas para a garantia dos direitos de autores no país: "A propriedade literária e artística é inviolável como a propriedade em geral; goza das mesmas garantias e transmite-se hereditariamente sem limitação de tempo e sem distinção de nacionalidade". ${ }^{13} \mathrm{Em}$ um único golpe, o autor procurou responder aos principais questionamentos colocados contra os direitos autorais. Aos que desconsideravam a validade da propriedade literária, afirmava-a como um direito inviolável, na medida em que seria comparável ao princípio geral da propriedade, tão caro à sociedade moderna. Estaria aquele direito protegido contra os delitos, com garantias semelhantes às que protegiam a propriedade privada. Além disso, Alencar expôs com intransigência sua posição sobre a duração dos direitos dos autores. Ao excluir qualquer limitação de tempo ao gozo daqueles direitos, o autor opunha-se até mesmo à grande maioria das propostas favoráveis, tendo em vista que normalmente indicavam alguma limitação, ainda que estabelecesse prazos que venceriam apenas após a morte dos autores.

Alencar procurou tratar questões como a reprodução das obras alheias, o plágio $e$ as imitações, a publicação pela imprensa de comunicações orais e a reutilização de artigos veiculados em periódicos. Tratou também da transmissão de direitos sobre a obra por meio de contratos e estabeleceu a necessidade de um registro para garantia de gozo dos direitos. A maior novidade presente no texto, em relação às iniciativas anteriores, foi a definição da essência da obra artística e literária sob três aspectos, a saber: o título, que seria a síntese da obra, que a especificaria e resumiria; a forma, que seria a configuração exterior da obra, seu aspecto; ${ }^{14}$ por último, haveria também a contextura, compreendendo o método e a organização utilizada para construir a obra, podendo ser geral, quando empregada em outros trabalhos (como no caso da divisão utilizada numa obra de direito constitucional ou de medicina para organização dos conhecimentos) ou específica, quando consistisse em novidade na disposição das matérias ou do encadeamento da obra literária.

Mais importante, no entanto, era reverter a falta de reconhecimento do caráter de propriedade ao domínio do escritor sobre seus textos. Isso constituía, para Alencar, um confisco pelo Estado dos direitos desses indivíduos que tinha como base uma compreensão equivocada da produção cultural. Segundo defendeu, a própria jurisprudência mostrava-se contrária à propriedade intelectual, validando o argumento de que "as produções do espírito não são [...] suscetíveis de ocupação. Acham-se no mesmo caso do ar e da luz; são riquezas universais, que não podem cair

12 ALENCAR, J. M. Propriedade litteraria. Annaes do Parlamento Brazileiro. Rio de Janeiro: Typ. Imperial e Constitucional de J. Villeneuve \& Cia., t.III, 1875.

${ }^{13}$ ALENCAR, Propriedade litteraria..., p. 28.

${ }^{14}$ Mantendo seu interesse em marcar a igualdade entre propriedade intelectual e a propriedade geral, Alencar compara esse aspecto à superfície resguardada pelo direito de propriedade territorial. 
no domínio privado"15. Alencar argumentou que comumente defendia-se que as criações não formariam um produto de domínio individual, mas, pelo contrário, resultariam de um tipo de missão confiada pela sociedade aos pensadores. Pertenceriam à sociedade como um todo $e$, de forma mais generalizada, à humanidade mesma.

Especialmente durante o segundo e terceiro quartos do século XIX ocorreram debates generalizados sobre a justeza dos direitos relacionados à propriedade literária. Considerava-se que as ideias que constituíam as obras resultariam da experiência social dos autores, de seu contato com aquilo que o desenvolvimento da cultura lhes permitia. Segundo esse ponto de vista, seu direito não seria, com efeito, apenas seu, mas sim de todos aqueles que conviviam e partilhavam as experiências sociais, produzindo e consumindo cultura. Os direitos autorais consistiriam, dessa maneira, em usurpação de um direito social generalizado ${ }^{16}$. Na esteira dessa discussão foi que se procurou estabelecer limitações ao direito, abrindo maior possibilidade de usufruto livre dos produtos culturais por parte da sociedade.

A este tipo de proposição, Alencar respondia com uma diferenciação entre civilização, pensamento e literatura, aplicando certa tônica ao fato de ser esta última uma produção artística, uma ocupação que não consistiria mais no pensamento abstrato, mas sim em um resultado do trabalho inventivo do autor. O que deveria ser protegido, portanto, não seria a ideia, mas o produto resultante do trabalho empreendido. A civilização não seria defendida através do confisco aos escritores dos direitos sobre as criações de seu espírito. Na obra, segundo Alencar, estariam expressos os traços da personalidade do autor, o que lhe daria individualidade diante de todo conhecimento que se relacionasse com ela. Ainda que integrasse uma corrente de pensamento ou fosse constituída de conhecimentos gerais alcançados pela coletividade, a maneira de dispor os assuntos, as soluções e, em suma, o resultado final dependeria do autor que seria por ela responsável.

Juridicamente, afirmou que a produção literária e artística era bem caracterizada, constituindo um fruto direto do trabalho do autor. Como o deputado Aprígio Guimarães, Alencar sustentou que a lei sobre propriedade literária deveria garantir, também, a propriedade das obras de autores estrangeiros publicadas em outros países, destacando a importância de que os governos dos outros países assegurassem a reciprocidade de tratamento para as obras publicadas no Brasil.

Outro questionamento imposto contra a aceitação jurídica da propriedade literária em suas primeiras discussões, e que foi respondido por José de Alencar no primeiro artigo de sua proposta legislativa, tem relação com a capacidade do autor de dispor de seu direito por meio de herança. Considerando o direito ainda como privilégio, grande parte dos que concediam o domínio econômico dos autores sobre suas obras, compreendiam, no entanto, que, uma vez morto o autor, estaria extinto o domínio sobre a obra. Em suma, seus herdeiros não teriam direito sobre a produção do escritor morto. Após morto o autor, estariam extintos os seus direitos morais sobre a obra, uma vez que a pessoa responsável por ela não mais existia. O direito

\footnotetext{
${ }^{15}$ ALENCAR, Propriedade litteraria..., p. 29.

${ }^{16}$ BITTAR, Carlos Alberto. O poder Legislativo e o direito de autor. Revista de Informação Legislativa, v. 26, n. 101, p. 135-146, jan./mar. 1989, p. 139.
} 
econômico, no entanto, seria perpetuado sem limitações, o que para muitos não parecia justificado. Alencar, em resposta, não propôs limitações aos direitos dos herdeiros, talvez por considerar o trabalho literário pouco rentável mesmo no correr de muitos anos de retorno resultante da venda de um livro. Para o romancista, "o bom livro é, no Brasil, e por muito tempo será para seu autor, um desastre financeiro. $\mathrm{O}$ cabedal de inteligência e trabalho que nele se emprega daria em qualquer outra aplicação lucro cêntuplo" ${ }^{17}$. Parecia-lhe, portanto, justificável garantir aos familiares a possibilidade de receber o retorno que em vida o autor jamais receberia pelo trabalho empreendido na construção de sua obra.

Garantir o retorno do trabalho ao autor, portanto, pressupunha resguardar a obra das ações de contrafação que poderia sofrer, bem como evitar qualquer tipo de utilização indevida das ideias resultantes do trabalho do autor. Nesse sentido, a oposição ao plágio era também exposta no projeto. Havia uma ressalva quanto à possível confusão entre essa atitude e as práticas legítimas da imitação e da citação que deveriam ser distinguidas sem generalizações. No artigo 11, o projeto estabelecia que questões de plágio e contrafação deveriam ser decididas por um júri composto por três escritores ou, em casos que envolvessem outro mister, artistas da especialidade da contrafação julgada. Além de estabelecer a existência do domínio dos autores sobre suas obras, Alencar propunha ainda a definição de uma nova função social para os seus pares, que poderiam exercer o papel de juízes diante de casos que envolvessem seu tipo de ocupação. A iniciativa de José de Alencar demonstrou a preocupação dos escritores com as tomadas de decisão referentes a seu fazer. Alencar retomou temas discutidos pelas propostas anteriores $e$ trouxe novidades, como a concentração sobre um tratamento mais estético do que comercial da propriedade intelectual, além de oferecer junto da minuta da lei uma justificação pormenorizada em que buscava responder a possíveis oposições.

Em 1882, Tobias Barreto ocupou a seção de jurisprudência nas páginas do Diário de Pernambuco para tratar do tema. Intitulado didaticamente "O que se deve entender por direito autoral", seu artigo apresentava uma defesa do abandono da expressão usualmente empregada de "propriedade literária" em favor de "direito autoral" ${ }^{18}$. A noção de posse que se impunha sobre o pertencimento da obra aos escritores geraria, para ele, dificuldades jurídicas no tratamento da questão, além de ignorar uma gama de direitos implicados na publicação das obras artísticas, para além das literárias. Referia-se às duas dimensões de direito que incidem sobre o problema, uma vez que sendo produto do trabalho dos autores, suas obras constituiriam seu patrimônio, mas também seriam elas provenientes de seu espírito. Analisando opiniões diversas de juristas europeus a respeito da questão dos direitos autorais, Tobias Barreto procurou demonstrar que seria mais apropriado tratar de "direitos" em vez de "propriedade". O autor foi um importante defensor dessa interpretação do direito autoral entre os brasileiros, mas a polêmica perdurou ainda até as décadas seguintes.

\footnotetext{
${ }^{17}$ ALENCAR, José de. Como e porque sou romancista. Porto Alegre: Mercado Aberto, 1998, p. 75.

${ }^{18}$ MENEZES, Tobias Barreto de. O que se deve entender por direito autoral. Diário de Pernambuco. 21 de junho de 1882 .
} 
Onze anos após a proposta de José de Alencar, novamente o legislativo avaliava um projeto de lei relacionado aos direitos de autor, proposto por Diogo Velho Cavalcanti de Albuquerque. Tomando como base a legislação belga e em sintonia com as proposições de Tobias Barreto quanto à denominação da temática como "direitos autorais", o senador estruturou toda a sua proposta buscando definir $e$ organizar os direitos de autores sobre obras literárias, musicais e plásticas. Nesse movimento, buscava atualizar a discussão, uma vez que o projeto de Alencar era marcado pelas "diferenças de doutrina e direito que o progresso [tinha] trazido". ${ }^{19}$ Demonstrava, então, a preocupação em alcançar todos os criadores de obras estéticas, com o objetivo de garantir-lhes o gozo do retorno financeiro e social resultante do consumo de suas obras.

Dividido em cinco capítulos, o projeto de Diogo Velho tratava do direito do autor em geral, no capítulo um; do direito de autor sobre obras literárias, no capítulo dois; do direito de autor sobre obras musicais, no terceiro capítulo; e do direito de autor sobre obras plásticas, no quarto. O quinto e último capítulo tratava, por sua vez, da contrafação e das ações previstas para sua repressão. Cada artigo, na verdade, correspondia a um capítulo do projeto, com exceção do artigo sexto, que seguia o artigo anterior no quinto capítulo, dedicado à repressão da contrafação. $\mathrm{O}$ projeto evidenciava o interesse em definir o que vinha a ser "direito autoral" e organizar como isso se relacionava com os diferentes tipos de obras artísticas. Após esse esforço eram dispostas as práticas consideradas apropriadas para a repressão das ações que contrariassem tais direitos. Como de resto ocorreu nos projetos anteriores, Diogo Velho respondia questões entre as mais discutidas em relação aos direitos autorais. Estabeleceu logo no primeiro artigo a duração do gozo desse direito enquanto o autor vivesse, e mais cinquenta anos após sua morte. Tratava ainda das obras colaborativas ou anônimas bem como das traduções. Em todos os casos, procurou garantir as maiores garantias possíveis.

O texto apresentado trazia também importantes "notas explicativas". Nelas, o legislador buscou evidenciar as bases utilizadas na redação do projeto. Sobre o primeiro capítulo, Diogo Velho expôs algumas correntes do direito que interpretaram de formas diferentes a natureza e extensão dos direitos autorais com o passar dos anos. Para tanto, comparou as tradições do direito francês e alemão: da primeira tradição comentou que seria mais propensa a interpretar o domínio autoral sobre suas obras como um verdadeiro direito de propriedade, similar ao proprietário de terras que delas podia dispor; no caso alemão, comentou que o direito de autor consistiria antes numa concessão da lei, uma graça mais pendente ao privilégio. Passou também em revista jurisconsultos belgas, para os quais os direitos de autor constituíam novo tipo de direito que, além das manifestações literárias e artísticas, protegia as inovações científicas, as marcas de fábrica, os planos de construção, entre outros.

\footnotetext{
${ }^{19}$ ALBUQUERQUE, Diogo Velho Cavalcanti de. Fala do senador Diogo Velho. Annaes do Senado do Império do Brazil: anno de 1886. Livro 5. Sessão de 6 de outubro de 1886, p. 314. Brasília: Secretaria Especial de Editoração e Publicações - Subsecretaria de Anais do Senado Federal. Transcrição. Disponível em http://www.senado.leg.br/publicacoes/anais/pdf/Anais_Imperio/1886/1886\%20Livro\%205.pdf. Acesso em 08/06/2016.
} 
Seguindo sua exposição, o documento destaca a centralidade do trabalho do autor no estabelecimento de seu direito sobre aquilo que produziu, afirmando que a "causa legítima da apropriação é o trabalho do homem"20. Este fator define a possibilidade de criar sobre os textos um direito de propriedade. Sobre esse aspecto, o senador se deteve para demonstrar a argumentação contrária ao direito análogo ao da propriedade exercido sobre obras intelectuais. Valorizando, portanto, a ação criadora do autor, aproxima os direitos autorais daqueles voltados às propriedades territoriais, demonstrando que a controvérsia não teria relação com os direitos exercidos sobre as obras ou sobre as terras. Existiriam, apenas, diferenças inerentes aos objetos do direito e não a este. Dessa maneira, Diogo Velho questiona se seria possível, como ocorre no direito sobre terras, dispor e gozar das obras artísticas e literárias, ao que prontamente responde que sim e ainda destaca: "a diferença consiste apenas no modo: as concepções intelectuais não podem, certamente, ser usadas ou empregadas como as coisas materiais" ${ }^{21}$. Seja no modo, seja na coisa, fato é que, segundo o senador, os direitos os autores os licenciam para dispor dos frutos de sua intelectualidade.

Para Diogo Velho, portanto, o autor exerceria o direito sobre sua obra, ao mesmo tempo, valendo-se da liberdade para dela tirar o possível proveito material pela publicação, apresentação ou qualquer outro meio de aproveitamento pecuniário de sua invenção $e$, por outro lado, resguardando para si as consequências do reconhecimento da beleza ou da utilidade de seu trabalho. As explicações do capítulo primeiro estendem-se um pouco mais, mas não avançam sobre questões tão complexas quanto a definição do direito e dos modos de seu aproveitamento pelos autores.

De resto, até comentar o último capítulo, referente às punições estabelecidas contra as afrontas ao direito de autor, o texto segue como explicação geral e mais rasa das disposições apresentadas. Atendo-se ao último capítulo do projeto, o deputado discorre sobre os critérios para definição do que fosse considerado contrafação, trabalho necessário para o estabelecimento de ações punitivas ao delito. Nesse sentido, para que ela existisse, era necessário que ocorresse reprodução da obra de qualquer maneira que não observasse o consentimento de seu auto, mas apenas poderia ser considerada como delito a ação que causasse prejuízo ao autor, fosse ele material ou moral.

O projeto de Diogo Velho, juntamente com suas notas explicativas constituiu importante meio de propagação da discussão relativa aos direitos autorais. Visando disciplinar o mercado literário e artístico, sua iniciativa contribuiu também para demonstrar a existência de tentativas de enquadramento da produção letrada, nas quais interessava reforçar os ideais de inovação na produção artística e estabelecer a posição do autor nacional, garantindo-lhe proteção em detrimento dos estrangeiros ${ }^{22}$.

\footnotetext{
${ }^{20}$ ALBUQUERQUE, Fala do senador Diogo Velho..., p. 317.

${ }^{21}$ ALBUQUERQUE, Fala do senador Diogo Velho..., p. 317.

${ }^{22}$ Lembre-se, aqui, que a proteção era voltada também aos autores estrangeiros domiciliados no Império, excluindo, na prática, todos os outros. A justificativa para essa disposição dizia respeito à necessidade de construção de acordos de reciprocidade diplomática que garantissem também a proteção de autores brasileiros em outros países.
} 
Após indicação de Benjamin Constant para o Ministério da Instrução Pública, em 1890, o jornalista e escritor Pardal Mallet publicou uma carta aberta ao novo ministro tratando de questões relativas ao direito autoral. Dividida em seis partes, a carta registrava a opinião do escritor a respeito da regulação da atividade literária no Brasil, tocando questões como o retorno pecuniário aos autores e considerando os plágios como uma atitude que enfraquecia a cultura nacional. Segundo Mallet, os direitos autorais, que distingue do termo propriedade literária, constituíam a forma mais correta para tratar as garantias ao sustento dos literatos. Mallet, se opondo ao posicionamento combatido também por Alencar, em 1875, defendia que na doutrina do direito autoral, com a substituição defendida do conceito de propriedade pelo de trabalho, o esforço artístico emergiria como uma atividade como outra qualquer, necessária e proveitosa à coletividade, mas que deveria primeiramente aproveitar ao trabalhador. Com essa elaboração, procurou acomodar as questões polêmicas relacionadas à retribuição pecuniária ao esforço do artista, procurando solucionar os problemas enfrentados por diversos literatos brasileiros quanto a sua subsistência.

Para o escritor, era da falta de compreensão da justiça dessa retribuição que se originavam os problemas das classes artísticas do país, mas nada era tão danoso quanto a ausência de um sentido de classe que unisse os trabalhadores das Letras. Nesse sentimento autonomista que atingiria todos os escritores, Mallet localizava "uma manifestação inconsciente da superioridade intelectual do artista", ${ }^{23}$ um reforço de imposição da originalidade individual, poderíamos dizer. Nesse sentido, um dos pilares da nova organização do campo literário causava um dos principais problemas à afirmação da atividade autoral. $\mathrm{O}$ escritor considerou serem naturais, portanto, as dificuldades enfrentadas para a formação de associações de artistas no Brasil, concluindo que o individualismo constituía o centro da questão. Uma vez que o ego constitui uma dimensão bastante importante nas disputas relativas ao direito autoral, é interessante atentar para sua relevância negativa sobre a montagem de iniciativas associativas que fortaleceriam, ao menos em teoria, as garantias relacionadas ao trabalho intelectual. Era claro seu objetivo de afirmar serem todos operários das Letras, centralizando a questão sobre o trabalho que realizavam, pelo qual deveriam ser remunerados. Nesse sentido, Mallet buscou demonstrar como diversas profissões envolvidas na indústria livreira careciam de proteção. Sobre traduções ilegais, por exemplo, Mallet destacou a facilidade em apropriar-se de textos estrangeiros. Tal problema gerava o inconveniente de destinar maior esforço para a tradução de obras estrangeiras que para a criação brasileira de obras originais. Outro problema eram os chamados "trabalhos de tesoura" ${ }^{24}$, apropriações indevidas de textos de diversos formatos por jornais brasileiros. Era comum deparar com o reaproveitamento de artigos de outros jornais ou mesmo a republicação sem referências, por não haver leis que assegurassem direitos autorais. O tema foi, aliás, tratado pela maioria dos projetos de lei apresentados desde a década de 1850. Não é possível perseguir até que ponto a carta teve impacto no cenário cultural e afirmar se ela influenciou a definição da legislação seguinte, mas é certo que nela encontra-se registrado o estado

\footnotetext{
${ }^{23}$ MALLET, João Carlos de Medeiros Pardal. Direito Autoral, Carta aberta a Benjamin Constant. Gazeta de Notícias, Rio de Janeiro, 26 abr./1 mai./3 mai. de 1890.

${ }^{24}$ MALLET, Direito Autoral....
} 
das discussões sobre a temática dos direitos autorais no Brasil, ao final do século XIX.

No bojo dos debates sobre os direitos dos autores, em 1893, o deputado Augusto Montenegro e o artista Pedro Américo de Figueiredo e Mello apresentaram também cada um a sua proposta de legislação. A contemporaneidade das propostas causou discussões acaloradas em plenário ${ }^{25}$, mas apresentavam diferenças importantes na forma e no conteúdo relacionado à defesa dos direitos autorais. A abordagem comparativa, colocando em confronto propostas distintas, parece-nos útil para ressaltar as principais características de cada um desses projetos.

O projeto apresentado por Pedro Américo agrupava seu conhecimento a respeito da questão dos direitos autorais, acumulado em suas participações em congressos e outros eventos ocorridos, principalmente, na França. Fazendo referência aos projetos anteriores, encaminhados por José de Alencar e Diogo Velho Cavalcanti de Albuquerque, apresentou, então, o seu próprio projeto, pretendendo oferecer uma contribuição que superasse uma mera compilação dos projetos anteriores. Dois anos antes, os governos de Brasil e França haviam assinado um tratado de proteção à propriedade literária. A convenção não foi, porém, confirmada pela Comissão de Diplomacia e Tratados do Congresso Nacional brasileiro. Os legisladores, não sem muita discussão, acabaram por rejeitar, em 1893, a assinatura do tratado. Considerando, por certo, um equívoco o posicionamento brasileiro em relação ao tratado, Pedro Américo evocou seus conhecimentos e experiência nos negócios artísticos para oferecer ao Congresso um projeto que pudesse regular as questões ora em discussão.

O projeto de Pedro Américo procurava garantir o gozo dos direitos autorais a todos os produtores de obras artísticas, literárias e científicas "de sua própria concepção, ou composição". A partir dos artigos $1^{\circ}$ e $2^{\circ}$ pode-se compreender a separação dos direitos autorais em relação à propriedade literária, uma vez que esta é assegurada e definida no segundo artigo, além de ser exposta pelo artigo $4^{\circ}$ a independência de um direito em relação ao outro. Se o direito autoral garantia ao responsável pela produção da obra o direito de assiná-la e decidir sobre sua finalidade, o direito de propriedade conferia o domínio sobre a alienação da obra, de sua reprodução e exposição. Como a maioria dos projetos anteriores, a proposta de Pedro Américo estabelecia um prazo de vigência para os direitos de propriedade literária, no caso, defendendo o gozo vitalício pelo autor mais cinquenta anos após sua morte por seus herdeiros ou representantes legais.

$\mathrm{Na}$ última parte do projeto, referente às punições das violações dos direitos de propriedade, Pedro Américo dispunha sobre as citações, adaptações ou transcrições que não objetivavam ganhos comerciais como intervenções que não constituíam violações do direito de propriedade literária e artística, uma vez que apresentassem "caracteres de evidente originalidade não contidas na obra inicial". ${ }^{26}$ Por outro lado,

\footnotetext{
${ }^{25}$ A diferença nas datas de apresentação dos projetos é menor que um mês. Pedro Américo expôs sua proposta na sessão de 12 de julho de 1893 e logo depois, em 7 de agosto do mesmo ano, Montenegro apresentou seu projeto.

26 AMÉRICO, Pedro. Projeto de lei de autoria de Pedro Américo sobre o direito autoral. Annaes da Camara dos deputados, p. 224-226. 12 jul. 1893, p. 226. Rio de Janeiro: Imprensa Nacional, 1894. Disponível em http://imagem.camara.gov.br/diarios.asp?selCodColecaoCsv=D. Acesso em 08/06/2016.
} 
as críticas polemistas com avaliação de obras artísticas ou científicas feita com objetivo de prejudicar o autor, poderiam incorrer em violação dos direitos dos autores sobre suas obras, sendo punida como tal.

Também no bojo das discussões desenvolvidas no interior da Comissão de Diplomacia e Tratados sobre a convenção literária com a França, de 1891, o deputado do Pará, Augusto Montenegro apresentou sua proposta de regulação. Seu objetivo seria propor uma lei sobre a questão que não ficasse atrelada a disposições estabelecidas por outro país. Sob o argumento de manutenção da soberania brasileira, portanto, o deputado propunha uma lei que ele mesmo declarou ser uma adaptação da alemã referente à questão. Após uma rápida discussão com Pedro Américo, Montenegro apresentou sua proposta, que avançava sobre as questões envolvidas com novidades em relação aos projetos anteriores.

Os direitos de autor seriam garantidos também aos estrangeiros, contanto que tivessem no Brasil um representante legal, algo muito próximo do que havia sido proposto em outras ocasiões. Na contramão do que estabeleciam os projetos anteriores, a limitação de tempo para gozo dos direitos pelos herdeiros ou representantes após a morte do autor ficava limitado a apenas dez anos, após o que se encontrariam as obras em domínio comum, que posteriormente foi nomeado domínio público. De seu projeto ficava claro o interesse em controlar o que se declarava em obras artísticas e literárias. $\mathrm{O}$ artigo $4^{\circ}$ estabelecia que o gozo dos direitos estaria limitado àquelas obras que trouxessem o nome do autor estampado. Por isso, obras anônimas, e mesmo pseudônimas, estariam excluídas da proteção do direito autoral.

O projeto de Montenegro conferia aos autores um controle sobre a utilização de suas obras, para montagem de espetáculos teatrais, traduções e mesmo adaptações, prática disciplinada pela primeira vez por sua proposta. As obras de autores nacionais que não fossem originalmente concebidas para $\mathrm{o}$ teatro não poderiam ser representadas, salvo nos casos em que tivessem autorização concedida pelo autor. Os autores estrangeiros sem representantes legais no país, contudo, não tinham esse direito garantido.

Os últimos artigos do projeto definiam o que se deveria entender por "contrafação" e estabeleciam punições dirigidas aos contrafatores. Entendendo como contrafação "toda reprodução parcial ou integral, fraudulenta ou de má fé, de uma obra literária, científica ou artística, [...] por quaisquer processos mecânicos, sem o consentimento do seu autor" 27 , o projeto estabelecia como punição a apreensão dos objetos contrafeitos e pagamento de multa. Além disso, o deputado defendia a destruição dos utensílios empregados na prática do delito.

A proposta de Montenegro serviu de base para discussões que se estenderam por cinco anos. Em 1894, do interior da Comissão de Instrução Pública e sob a relatoria de José Joaquim de Campos da Costa de Medeiros e Albuquerque, outro projeto, muito baseado nos primeiros apontamentos de Augusto Montenegro, foi apresentado à Câmara. As discussões realizadas durante aquele ano revelavam a grande

27 MONTENEGRO, Augusto. Projeto de lei de autoria de Augusto Montenegro sobre o direito autoral. Annaes da Camara dos deputados. Rio de Janeiro, p. 157-160. 07 ago. 1893, p. 159. Disponível em http://imagem.camara.gov.br/diarios.asp?selCodColecaoCsv=D. Acesso em 08 /06/2016. 
concordância entre os dois proponentes, guardando-se alguma reserva, sobretudo, em relação aos entendimentos a respeito do direito de tradução. $\mathrm{O}$ projeto de Medeiros e Albuquerque abandonava uma disposição defendida por Montenegro que dizia respeito à reserva da exploração do direito de tradução para o próprio autor. Outra questão que diferenciou as propostas relacionava-se à duração do direito. Se para Augusto Montenegro parecia positivo resguardar o direito dos autores vitaliciamente e por mais dez anos após sua morte, Medeiros e Albuquerque preferiu estabelecer a duração do gozo do direito por cinquenta anos a contar da data de publicação da obra. Montenegro, contudo, declarou concordar com a mudança afirmando que "o nobre deputado [...] e a ilustre comissão admitem um sistema, a meu ver melhor, que aquele que eu havia apregoado e no qual existia um elemento incerto, qual é a morte, que podia aumentar ou diminuir o prazo da garantia" ${ }^{28}$. $\mathrm{Na}$ nova redação proposta, portanto, ficaria mais imparcial e melhor definida a extensão temporal da garantia dos direitos dos autores.

Após discussões, o projeto ainda seguiu para o Senado, sendo promulgado, na forma de decreto, em agosto de 1898. O decreto guardava traços evidentes do projeto de 1893, como a definição do que não seria considerado como contrafação, reservando certa liberdade de ação autoral à citação, adaptação e imitação. Também as definições do que se entenderia por direitos de autor e, especialmente, de "obra literária, científica ou artística" presentes na lei deveram bastante ao projeto de Augusto Montenegro.

Dos meandros das discussões sobre a lei de direitos autorais brasileira, durante a década de 1890, acompanhando a publicidade da questão nos principais periódicos em circulação, percebe-se a supervalorização da atuação do deputado Medeiros e Albuquerque, sobretudo após a fundação da Academia Brasileira de Letras, em 1897. É certo que sua capacidade de articulação resultou na votação de um projeto de lei sobre os direitos autorais, mas igualmente certo é que a concepção do projeto deveu muito à proposta apresentada por Augusto Montenegro, que continuou contribuindo com o desenvolvimento da lei nos debates posteriores.

Os esforços de definição e de institucionalização dos direitos autorais no Brasil responderam também ao interesse de caracterização do fazer do escritor nacional. Atuando como solução frente às dificuldades financeiras enfrentadas pela maioria dos escritores, as garantias expressas em lei em relação aos direitos dos autores possibilitariam a estes agentes culturais serem identificados enquanto tais, além de permitirem receber algum retorno pelo trabalho empreendido. Ainda que o retorno não fosse suficiente, como destacou José de Alencar e a maioria dos escritores do XIX, o demorado processo de constituição do direito autoral no Brasil - que vai da primeira expressão legal relacionada a publicações de textos, na década de 1830, até

${ }^{28}$ ANNAES DA CAMARA DOS DEPUTADOS. Ordem do dia. Primeira sessão da Segunda Legislatura. Sessões de 1 a 30 de agosto de 1894, p. 122-126. Rio de Janeiro: Imprensa Nacional, 1895, p. 124. Disponível em http://imagem.camara.gov.br/dc_20b.asp?selCodColecaoCsv=A\&Datain=13/8/1894\#/. Acesso em 08/06/2016. 
a sua inclusão final no texto da lei brasileira, no final da década de 1890 - promoveu um ambiente favorável à reunião de grupos intelectuais suficientemente legitimados para a construção de uma coletividade reconhecida como extrato mais elevado da cultura brasileira à época.

\section{$\operatorname{soc}$}

\section{RESUMO}

No presente artigo procuramos analisar as principais propostas relacionadas à regulamentação dos direitos autorais ocorridas no Brasil durante o século XIX, no objetivo de evidenciar as principais demandas existentes em relação ao reconhecimento do trabalho literário. Seguindo os debates legislativos, procuramos determinar a importância dessa atuação na definição das práticas literárias, bem como avaliar seu papel na instituição da figura autoral enquanto proprietária dos textos literários. A garantia de pagamento para os autores de textos literários demonstrou-se apenas um dos fatores implicados nas negociações referentes à concretização legislativa da defesa dos direitos autorais. Palavras Chave: Direitos autorais; Literatura brasileira; Autoria.

\begin{abstract}
This article analyzes the main proposals related to the regulation of copyright in Brazil during the 19th century, in order to highlight the main demands related to the recognition of literary work. Following the legislative debates, we try to determine the importance of this action in the definition of literary practices, as well as to evaluate its role in the institution of the author figure as owner of the literary texts. The guarantee of payment for authors of literary texts was only one of the factors involved in the negotiations regarding the legislative implementation of the defense of copyright.
\end{abstract}

Keywords: Copyright; Brazilian literature; Authorship.

Artigo recebido em 03 nov. 2017.

Aprovado em 18 jun. 2018. 